\title{
Ames Stereo Pipeline-derived Digital Terrain Models of Mercury from MESSENGER Stereo Imaging
}

\author{
Caleb I. Fassett ${ }^{\dagger}$ \\ Department of Astronomy, Mount Holyoke College, South Hadley, MA 01075 \\ ${ }^{\dagger}$ Now at NASA Marshall Space Flight Center, Huntsville, AL, 35805 \\ *Corresponding Author Contact Information: \\ Department of Astronomy \\ Mount Holyoke College \\ 50 College St. \\ South Hadley MA 01075 \\ 413-538-2240 \\ Email: cfassett@mtholyoke.edu
}

Submitted to Planetary and Space Sciences: March 1, 2016

Revised version: August 26, 2016

Second Revised Version: September 30, 2016

Keywords: Mercury, surface; Topography; Stereo Image Processing; Hollows; Pits 


\begin{abstract}
In this study, 96 digital terrain models (DTMs) of Mercury were created using the Ames Stereo Pipeline, using 1456 pairs of stereo images from the Mercury Dual Imaging System instrument on MESSENGER. Although these DTMs cover only $~ 1 \%$ of the surface of Mercury, they enable three-dimensional characterization of landforms at horizontal resolutions of $\sim 50-250$ $\mathrm{m} /$ pixel and vertical accuracy of tens of meters. This is valuable in regions where the more precise measurements from the Mercury Laser Altimeter (MLA) are sparse. MLA measurements nonetheless provide an important geodetic framework for the derived stereo products. These DTMs, which are publicly released in conjunction with this paper, reveal topography of features at relatively small scales, including craters, graben, hollows, pits, scarps, and wrinkle ridges. Measurements from these data indicate that: (1) hollows have a median depth of $\sim 32 \mathrm{~m}$, in basic agreement with earlier shadow measurement, (2) some of the deep pits (up to $\sim 4 \mathrm{~km}$ deep) that are interpreted to form via volcanic processes on Mercury have surrounding rims or rises, but others do not, and (3) some pits have two or more distinct, lowlying interior minima that could represent multiple vents.
\end{abstract}

\title{
1. Introduction and Background
}

Over the last decade, observations by the MESSENGER (MErcury Surface Space ENvironment, GEochemisty and Ranging) spacecraft have led to substantial improvements in the understanding of Mercury's geological, geochemical, and geophysical characteristics (Solomon et al., 2007). In addition, imaging by the Mercury Dual Imaging System (MDIS) (Hawkins et al., 2007) has provided the first globally complete mosaic of Mercury’s surface, giving us a view 
of a surface dominated by impact craters and tectonic and volcanic landforms (e.g., Prockter et al., 2016).

Topographic information is useful for enhancing the interpretation of this image data and determining the relief of landforms. MESSENGER data available for topography measurement of Mercurian landforms include laser ranging by the Mercury Laser Altimetry (MLA) (e.g., Zuber et al., 2012) and by analyzing MDIS images with stereo photogrammetric techniques (e.g., Preusker et al., 2011, 2012) or photoclinometry (e.g., Gaskell et al., 2008). Because of MESSENGER's elliptical orbit, MLA ranging was mostly limited to when the spacecraft was closest to its pericenter in the northern hemisphere; as a result, the density of measurements is highest at latitudes $>55^{\circ} \mathrm{N}$ and no ranging measurements exist south of $20^{\circ} \mathrm{S}$. For this reason, the MESSENGER team planned a systematic campaign of stereo imaging. In addition, specific targets for high resolution stereo were also planned and acquired.

Most past and current ongoing efforts to characterize the topography of Mercury from Mariner 10 (Cook and Robinson, 2000) and MESSENGER data (Oberst et al., 2010; Preusker et al., 2011, 2012) have focused on developing digital terrain models (DTMs) at regional-to-global topography scales. Thus, most publicly-released DTMs to date have had horizontal resolution of $\sim 1 \mathrm{~km} /$ pixel or above, which limits their applicability for characterizing small landforms. Only a few stereo models of Mercury at higher resolution have been described in the literature to date (Gwinner et al., 2012; Thomas et al., 2014a,b, 2015).

Therefore, the focus of this study was on creating numerous local-to-regional-scale high resolution DTMs with resolution of $\sim 250 \mathrm{~m} /$ pixel or better, covering as much of the Mercury surface as possible. Henrikson et al. (2015) reported that they are undertaking an effort broadly 
similar to this study, focused on deriving high-resolution stereo topography, using SOCET SET rather than the Ames Stereo Pipeline.

Two feature classes are described in this manuscript in somewhat greater detail to illustrate the type of geological observations that can be made using the derived topography, hollows (e.g., Blewett et al., 2011; Thomas et al., 2014c), and deep pits formed by pyroclastic volcanism (e.g., Head et al., 2008, 2009; Kerber et al., 2009, 2011; Gwinner et al., 2012; Goudge et al., 2014) and/or collapse (Gillis-Davis et al., 2009). The topography of these features is particularly worth examining because open questions exist about their topography in each instance. In the first case, the typical depth of hollows is worth further examination, as earlier work has relied on shadow measurements, which although a well-proven technique, have their own limitations and assumptions. In the case of the large volcanic pits, it has been suggested before that certain examples are on local topographic rises. Evaluating this is useful for determining whether the eruptions were associated with some amount of construction, or whether the process was mainly one of collapse and any associated deposits are mainly very thin.

\section{Datasets and Methods}

\subsection{Software}

The Ames Stereo Pipeline (v.2.4.2) (Broxton and Edwards, 2008; Moratto et al., 2010; Beyer, 2015; Shean et al, 2016) and the USGS Integrated Software for Imagers and Spectrometers (ISIS) (v.3.4.7, later upgraded through 3.4.10) (e.g., Anderson et al., 2004) packages were the primary tools used for photogrammetric processing. ISIS was used to ingest, calibrate MDIS data, and attach spacecraft attitude information, which were then fed to the Ames 
Stereo Pipeline on a stereo pairwise basis, as described in more detail in section 2.5. After processing, the stereo DTMs and associated orthoimages are imported to ArcMap for analysis.

\subsection{The MDIS instrument and MDIS image characteristics}

The MDIS instrument consists of two cameras, the Wide Angle Camera (WAC) and the Narrow Angle Camera (NAC) (Hawkins et al., 2007). Each camera has a 1024×1024 detector; the NAC has a $550 \mathrm{~mm}$ focal length and a $1.5^{\circ}$ field of view, while the WAC has a $78 \mathrm{~mm}$ focal length and $10.5^{\circ}$ field of view. (Note that these values are averages; in practice, the focal lengths of the cameras are known to be temperature dependent, which is taken into account in the MDIS camera model used in ISIS and the Ames Stereo Pipeline). Given these general characteristics, at a given distance from the planet, the NAC can acquire much higher resolution images of Mercury than the WAC, but over a much narrower portion of the surface. Thus, to obtain a global mosaic, most imaging of Mercury planned by the MESSENGER team used the NAC when far from Mercury (when imaging the southern hemisphere), and the WAC when near to the planet (when imaging the northern hemisphere). However, numerous exceptions exist, especially at specific targets of interest, and occasionally for reasons of happenstance; indeed, most of the topographic models described here are NAC image pairs in the northern hemisphere because these represent the highest resolution stereo opportunities obtained by MESSENGER.

The one-megapixel-resolution detector of MDIS means that a stereo DTM derived from a single image pair will have fewer pixels than is common for many cameras that the Ames Stereo Pipeline is presently being widely used to analyze. If the effective horizontal stereo resolution that can be achieved is a factor of $3 \times$ worse than the source images (e.g., see Ames Stereo Pipeline Manual, 2015), any single, perfectly overlapping pair will only have $\sim 340 \times 340$ pixels. 
Under ideal conditions where a high density of match points can be found and subpixel accuracies can be achieved, this factor of $3 \times$ might be somewhat reduced; for example, Gwinner et al. (2012) derived DTMs with horizontal resolution of $1.5 \times$ that of the source images with MDIS data. Regardless, however, the total amount of topographic information available from a single MDIS stereo pair is limited. Thus, the focus here was on making DTMs where multiple stereo pairs existed and it was possible to mosaic them into a continuous DTM.

\subsection{The MLA instrument and data characteristics}

The Mercury Laser Altimeter instrument (Cavanaugh et al., 2007) used lidar to measure

the topography of Mercury (with $<1 \mathrm{~m}$ ranging accuracy) when MESSENGER was within $~ 1600$ $\mathrm{km}$ of Mercury's surface; data are thus limited to north of $-20^{\circ} \mathrm{S}$. The spot size of each laser shot on the surface varied from 15 to $100 \mathrm{~m}$ depending on the range, and the along-track spacing of shots was typically $\sim 400 \mathrm{~m}$ (Zuber et al., 2012), although this varied with ranging distance and detectability of returns. Like other planetary lidar instruments, the resulting data provide highly accurate but sparse measurements of Mercury's topography. Even at latitudes that MLA was able to gather data, the cross-track gaps between laser profiles can be tens of kilometers.

A database of all individual MLA shots was created from the RDR files available on the PDS, and the data were filtered to retain only points with CHANID=0 in the MLA RDR files (the highest signal-to-noise ground trigger). This database was queried after stereo processing using the location of the resulting DTM; the local MLA data was then used as a geodetic control for improving the stereo models and as a tool for assessing the accuracy of the stereo products, as described below. 


\subsection{Available Data and Stereo Pair Identification}

Stereo pairs were identified using criteria following Becker et al. (2015) (see Table 1) using the MDIS PDS cumulative index file. Figure 1a shows the locations from each camera with overlapping images that are most amenable to stereo analysis existing through MESSENGER release 13 (data obtained through 9/2014), as well as the subset with each source image having resolution $\leq 100 \mathrm{~m} / \mathrm{pixel}$ (Fig 1b). Image pairs with each image having resolution $\leq 100 \mathrm{~m} /$ pixel (Fig. 1b) were the primary focus of this study, since, below this cutoff resolution, DTMs with effective spatial resolution $<\sim 250-300 \mathrm{~m} /$ pixel can be produced. This also limits most of the data analysis to targeted NAC pairs in the northern hemisphere, though a few WAC pairs were also processed in specific regions of interest and as test cases. For simplicity, only the WAC G filter was examined; this eliminated any available stereo acquired at different wavelengths.

\subsection{Stereo Image Processing}

After identifying candidate stereo pairs, each image was processed in USGS ISIS using mdis2isis, mdiscal, and spiceinit. The unprojected images were then matched using the Ames Stereo Pipeline's stereo application (see Table 2 for key parameters normally used in stereo.default). Occasionally, where alignment using point matching of unprojected image and local homography failed, map-projected images were input to stereo and the pairs were rerun. In this case, the only difference in Table 2 is that alignment-method was set to none.

The post-processing procedures for the resulting point clouds varied depending on the availability of nearby stereo data and sufficient MLA point data to tie the point cloud to the MLA reference frame. Where stereo data overlapped sufficiently, as usually was the case, point 
clouds were mosaicked to each other by applying a rigid translation to match the point clouds using Iterative Closest Point registration with the Ames Stereo Pipeline's pc_align tool (Beyer et al., 2014). This translation was calculated by comparing the clouds in the region of overlap and then applying the resulting derived rigid translation to the full cloud. Rotational transformation of the clouds during alignment was disabled after initial tests revealed that allowing rotation created anomalous tilts. This was a consequence of the region of overlap between neighboring clouds sometimes being very small.

The motivation for implementing this cloud-to-cloud mosaicking strategy was to remove seams between neighboring stereo point clouds and in the resulting DTMs. The original source of these offsets between nearby stereo pairs, which typically are a few hundred meters or less, are uncertainties in spacecraft position or instrument pointing. An alternative and more rigorous solution would be to resolve these errors with bundle adjustment or by simultaneously solving for stereo between multiple images (e.g., see Preusker et al., 2011). Nonetheless, the postprocessing solution used here generally appears to be effective as well. The mosaicked DTMs are all posted at a resolution chosen to be a factor of $3 \times$ worse than the worst input image. In practice, the effective horizontal resolution of each DTM varies somewhat depending on imaging conditions, texture, and the number of match points that were derived. Some local gaps exist on the final DTMs. These locations - often in shadow - had no valid match points during stereo matching.

Where MLA shot points were available to constrain the results, as was typically the case, the mosaicked DTMs and orthoimages were subsequently tied via rigid translation to the MLA reference frame with $p c \_a l i g n$. Where no MLA data was available, the final stereo products are located on the planet on the basis of their best guess position from the images' SPICE data and 
stereo processing, but are not tied to any other topographic model. Only the DTMs where MLA data were available give confident estimates of absolute positions and elevations on Mercury's surface, since uncertainties in the position and orientation of the spacecraft and camera can result in offsets in the resulting stereo DTM. Nonetheless, even where such external control is unavailable, the relative relief on derived DTMs produced by the Ames Stereo Pipeline has been shown to be reliable and useful for geologic applications (e.g., crater shape and morphometry; Watters et al., 2015). All elevation values in the DTMs are referenced to a sphere with radius of $2440.0 \mathrm{~km}$.

Orthoimages associated with each DTM scene were also produced using USGS ISIS. Mosaicking of the orthoimage for each component stereo pair in the scene was accomplished by importing the stereo-produced orthoimages into ISIS using gdal_translate to create ISIS2 images as a temporary intermediate, and then $p d s 2 i s i s$ to convert back to ISIS3 images. Each images' known projected geometry was attached in ISIS using maptemplate and maplab. Then, the mosaics were made near-seamless using blend, automos, and highpass.

Note that after the initial review of this manuscript, the final release of MLA data took place, and an update of the geolocation of the entire MLA dataset resulted. Additionally, a few details of the processing were changed as a result of reviewer comments. Thus, a wholesale reanalysis of the stereo DTMs was made to bring them to version 2. Comparison of the initial version 1 results and those from version 2 indicate that changes are almost entirely limited to horizontal translations resulting from the revised MLA dataset. For this reason, the results and measurements described in the rest of this study (with the exception of Table 3) have not been updated anew. 


\section{Results: Stereo DTMs and Uncertainties}

The full list of 96 processed DTMs (from 1456 source images) is given in Table 3, along with a brief description of the main features of interest resolvable by the DTM. This section provides an assessment of the uncertainties in these products.

\subsection{Estimated Precision and Accuracy}

Both the precision and accuracy of the topography inferable from stereo are dependent on factors that vary from scene to scene, so there is no single overarching answer to the question of how uncertain the DTMs are. Indeed, even within some of the mosaicked DTMs, there is variability in the uncertainty and effective resolution as the properties of the source image pairs varied across the scene.

One estimate for the accuracy of the stereo DTMs is direct comparison of measurements on the DTM with MLA measurements. One caution is that MLA points and the DTMs are measuring at different scales and the co-registration between the datasets is imperfect, even after alignment, so differences that arise are thus not the result of inaccuracy in the stereo DTM alone. Table 3 includes the raw difference between the Ames Stereo Pipeline-derived DTM and MLA, and the difference between the DTM and MLA after removing the $p c \_$align-derived rigid translation between the two datasets prior to the comparison. The first of these quantities can be interpreted as an estimate of the absolute geodetic accuracy of the stereo models without control (not removing systematic offsets), and the second is an estimate for the accuracy of the DTMs removing the bias between the two datasets. The second of these quantities is the more pertinent to consider, since it gives a sense for the typical magnitude of offset, most of which is due to uncertainty in the stereo DTM. 


\subsection{Inter-DTM comparisons and Effective Vertical Resolution}

For a number of the locations studied, multiple image sequences covered the same location. Three such locations are described below and shown in Figs. 2-4. These provide good examples of the quality of the DTMs derived, and because the DTMs in these locations overlap, it is possible to check their agreement with each other. Moreover, because the coverage of the same location in multiple DTMs of different resolution provides a useful look at the effective vertical resolution of the stereo measurement, or how much vertical relief the DTMs could discern for the given stereo pair resolution.

The effective vertical resolution is again dependent on a range of scene-specific conditions, the most important of which are the pixel resolution and the stereo convergence angle controlling the amount of parallax existing between the image pair. At stereo convergence angle of $\sim 20^{\circ}-30^{\circ}$, the effective vertical resolution is approximately the pixel resolution of the original source images, so a factor of $\sim 3 \times$ better than the post resolution of the DTM.

\subsubsection{Inter-DTM Comparison, Example 1: Eminescu Crater}

Eminescu Crater is one of the freshest craters of its size (D 125 km) on Mercury and has a small peak ring, consistent with it being close to the transition in size between complex craters and more typical peak ring basins (Schon et al., 2011). Two 170 m/pixel DTMs, 114E11N_0 and 114E11N_1, were created that cross Eminescu east-to-west and north-to-south, respectively (Fig. 2). The DTMs reveal that Eminescu has significant circumferential differences in its topography: the northern and eastern rims are $\sim 400-500 \mathrm{~m}$ higher than those to the west and south. In addition, impact sculpture (e.g., Fassett et al., 2009), or troughs created by the crater's 
ejecta, are present within 10-12 km of the rim to the crater's northern rim, but are not prominent in its other three quadrants. These differences likely reflect the fact that Eminescu was formed in a moderately oblique impact, as is typically the case.

The smooth deposits within Eminescu's rim and on its floor have been interpreted as impact melt (Schon et al., 2011), and small channels on the inner rim wall observable in the DTMs were likely carved by impact melt, as in the case for Tycho on the Moon (e.g., Hawke and Head, 1977). The impact melt ponds stand out in the DTMs as regions of approximately smooth topography. Since these were likely equipotential surfaces, deviations from a single elevation are likely a result of uncertainty in stereo matching. The range of elevations on these surfaces in both DTMs is a few tens of meters, consistent with the expected uncertainty in these products of $\sim<40-60 \mathrm{~m}$ (the original source image pixel resolution).

Without correcting the co-registration between the two datasets, the average pixel-topixel vertical difference between the two datasets is $\mu=38.1 \mathrm{~m}$ with standard deviation $\sigma=35.8 \mathrm{~m}$. However, there is an apparent horizontal offset of one-third of a pixel between the two DTMs that is partially the source of this difference (not corrected here). The existence of these systematic offsets is unsurprising given that the MLA data constraining the two DTMs is sparse (given the equatorial location), and the shots overlapping with the stereo model differ between the two pairs. Individual measurements of the relief on each DTM agree better with each other than the absolute elevations. This is true for all the DTMs; local elevation differences will always be more reliable on these datasets than their absolute geodetic accuracy.

\subsubsection{Inter-DTM Comparison, Example 2: Catullus Crater and Pit}


The interior of Catullus crater (Fig. 3) is covered by two DTMs (293E22N, 294E22N). A large pit is located near the central peak of Catullus that has been interpreted to be the result of pyroclastic volcanism (see section 4.2) (Head et al., 2008, 2009; Murchie et al., 2008; Robinson et al., 2008; Blewett et al., 2009; Kerber et al., 2009, 2011; Goudge et al., 2014; Thomas et al, 2014b,c). This crater and pit were referred to as "Unnamed Crater 1" by Kerber et al. (2011) and Goudge et al., (2014).

The internal consistency of the two DTMs in their area of overlap is excellent. The mean difference between $293 \mathrm{E} 22 \mathrm{~N}$ and $294 \mathrm{E} 22 \mathrm{~N}$ is $\mu=5 \mathrm{~m}$, with a standard deviation $\sigma=34 \mathrm{~m}$. Some of the differences that exist between the stereo DTMs are due to inexact co-registration of the two stereo models at the scale of one or two pixels; no attempt was made to optimize coregistration prior to assessing the residuals.

\subsubsection{Inter-DTM Comparison, Example 3: Praxiteles}

Three DTMs were constructed of the interior of Praxiteles crater using three different image sequences (299E27N_0, 300E26N_0, and 301E27N_0) with source image resolutions between $\sim 20$ and $\sim 55 \mathrm{~m} /$ pixel (Fig. 4). The DTMs resolve the wide variety of geological features in Praxiteles, including large pits, hollows, the crater's peak ring, and numerous smaller craters on the plains. Again, the internal consistency of these DTMs is excellent. The mean difference between 299E27N_0 and 301E27N_0 the mean offset $\mu=7 \mathrm{~m}$, with a standard deviation $\sigma=44 \mathrm{~m}$. Between 299E27N_0 and 300E26N_0, $\mu=14 \mathrm{~m}$ and $\sigma=31 \mathrm{~m}$.

\section{Results: Geological Applications}

\subsection{Topography of Hollows}


Hollows are small-scale, enigmatic, rimless depressions first resolved by MESSENGER high-resolution imaging data (e.g., Blewett et al., 2011) (although their bright signature had been apparent earlier, including in Mariner 10 data). The origin of hollows has been hypothesized to be the result of mass loss via sublimation, since hollows share many morphological characteristics with sublimation hollows in the "Swiss-cheese terrain" in the $\mathrm{CO}_{2}$ cap at Mars" south pole (Blewett et al., 2011).

To date, the topography of hollows has been assessed only with shadow measurements. Three studies have presented results: Blewett et al. (2011) give an average depth of $44 \mathrm{~m}$ for hollows in Raditladi and Vaughan et al. (2012) quote a depth of $~ 30$ m for hollows in Kertesz. The most extensive measurements to date were by Thomas et al. (2014c), who reported an average depth of $\mu=47 \mathrm{~m}(\sigma=21 \mathrm{~m})$ in 108 measurements of individual hollows from 27 different clusters, with a maximum depth of close to $\sim 100 \mathrm{~m}$ in the deepest case.

The topography of 125 hollows in Raditladi crater, Praxiteles crater (e.g., Fig. 4), and an unnamed $72-\mathrm{km}$ crater at $297^{\circ} \mathrm{E}, 1^{\circ} \mathrm{N}$ (297E13N_0 and $\left.297 \mathrm{E} 13 \mathrm{~N} \_1\right)$ were extracted where hollows are obviously resolved in the DTMs. Hollow depth was determined by outlining the rim of each hollow manually mapped orthoimages, removing a plane fit to this outline, then subtracting the minimum elevation within the rim from the median rim elevation. The resulting median depth is $34 \mathrm{~m}$, or expressed as an average, $37 \mathrm{~m}(\sigma=19 \mathrm{~m})$ (Fig. 5). Because many of the measurements are covered by multiple DTMs, duplicate measurements of individual features could be examined to assess the level of error on the depth, which is $\sim 40 \%$, which is unsurprising given the small scale of hollows and the inherent uncertainty in the DTMs. The distribution of measurements shown in Fig. 5 is more robust than the uncertainty in individual measurements. 
The results of these measurements suggest that hollow depth may vary somewhat between locales: measured depths in 297E13N are deeper than those in Raditladi by $\sim 50 \%$. Hollows in Zeami crater are potentially deeper still (100-150 m), although because of Zeami's location in the southern hemisphere, hollows are not very well resolved in the stereo DTMs (and are thus not included in the quoted averages or Fig. 5). If hollows are formed as a volatile material that is being lost via sublimation, these variations in hollow depth may reflect original variation in the thickness of the substrate of material that hollows form in. Verifying this finding will require additional observations, and would be a valuable target for high-resolution imaging with the upcoming BepiColombo mission.

\subsection{Topography of Large Pits}

Large pits that appear to be endogenic in origin are observed in many places on Mercury (Schultz, 1977; Head et al., 2008, 2009; Gillis-Davis et al., 2009; Kerber et al., 2009, 2011; Goudge et al., 2014; Thomas et al., 2014b). Mechanisms for forming these pits include explosive volcanism (e.g., Head et al., 2008; Kerber et al., 2009) and/or collapse (Gillis-Davis et al., 2009). The most prominent large pits have distinctive, bright deposits in their surroundings with red-spectral slopes, which have been interpreted to be deposits from pyroclastic eruptions that formed the pit; such deposits are observed around most of Mercury's pits but are not apparent in every instance. It is unclear whether pits form from different processes (e.g., via only collapse rather than explosive eruption), or whether those that lack significant surrounding spectral signatures are simply more degraded or have thinner deposits.

The topography of certain pits has been discussed before (e.g., Gwinner et al., 2012; Goudge et al, 2014; Di Achille et al., 2014; Rothery et al., 2014; Thomas et al., 2015), but the 
measurements enabled by the stereo DTMs produced are higher resolution and/or less sparse than earlier measurements (with the exception of the Gwinner et al., 2012 abstract). Here, sixteen large pits were analyzed by manually mapping the pit rim on orthoimages. The median rim topography and the lowest interior point were extracted to derive rim-to-floor depth (Table 4). In addition, median profiles of pit topography were derived by taking buffers at 500 meter increments inward and outward from the pit rims (Fig. 6).

The range of observed pit depths is somewhat broader than found by Goudge et al. (2014). In addition, some pits, particularly the largest ones, have rims or subtle, surrounding rises (Fig. 6), an observation also noted by Gwinner et al. (2012). For the pit labeled here as Caloris1 (the so-called kidney-shaped depression of Head et al., 2008), this has been suggested before on the basis of very challenging observations (Head et al., 2008; Rothery et al. 2014) which were taken to be consistent with the pit lying on a subtle rise or dome. Our data support the inference that this pit has a subtle, less-than-one-degree exterior slope, which in this case may extend up to $\sim 20 \mathrm{~km}$ from the vent rim, comparable in scale to the observed deposit radius (Kerber et al., 2011). Similar subtle rises are found around $\sim 1 / 3$ of the pits that were measured. In addition, NE Rachmaninoff has a steeper and narrower rim ( $<5 \mathrm{~km}$ wide $)$.

The most likely interpretation for both the observed rims and rises around these pits is that they are constructional (i.e., due to deposition from the eruptions that formed the observed pits). The fact that exterior slopes are most prominent around the largest pits (Fig. 6c) is consistent with deposits from larger pits being more prominent. It is presently hard to distinguish whether the lack of any rise around the shallower or smaller pits is mostly primary (i.e., due to smaller eruptions), or a result of secondary factors such as more significant 
degradation of smaller features. The fact that interior angles of the smaller features are less wellcorrelated with size than exterior angles suggests that degradation is not the sole factor, however.

In addition to the surrounding topography, stereo observations of the pit interiors also have implications for the formation of the pits. As inferred earlier in some instances (e.g., Kerber et al., 2011; Rothery et al., 2014), a number of the pits have multiple topographic minima on their interior (Table 4). Both these topographic characteristics and other observations such as planform shape suggest that individual pits may have been formed from multiple vents, likely sharing a magmatic source. This is consistent with the observation that pits are often commonly clustered together regionally as well.

\section{Data Availability}

The digital terrain models and their associated orthoimages described in this manuscript are available for other researchers to use at http://www.calebfassett.com/mercurydtms. The files are 32-bit geotiffs with embedded projection information that are verified to work in Arcmap but should work in a wide range of other software. Areas outside the images, or where gaps in matching occurred, were set to a data value of -10000. Available with each DTM are lists of the source image pairs that went into creating the terrain models.

\section{Conclusions}

The 96 digital terrain models described in this manuscript were created from 1456 image pairs in total, and support earlier work showing that high-resolution stereo models can be derived using MESSENGER MDIS data that are useful for geological analyses. Here, observations of hollows and pits are described to illustrate the derived stereo products usefulness. In particular, 
these measurements indicate that hollows have a median depth of $\sim 32 \mathrm{~m}$, which is in agreement with earlier shadow measurements but include many more features. The data also suggest that there may be regional variation in hollow depth, although this is close to the resolution limit of the DTMs and future observations (e.g., by BepiColombo) may help examine this further.

Stereo observations of the deep pits formed mainly via pyroclastic eruptions show that a number of these features have surrounding rims or rises, and the morphology of this raised topography varies between different vents. Large pits are more likely to have rims or rises in their surrounding topography, supporting the interpretation that these features are constructional. Finally, some pits have two or more distinct, low-lying interior minima that could represent multiple vents.

It is important to acknowledge that the goal of this project was to derive usable, useful DTMs over small-to-moderate sized regions at high-resolution to enable new geological analyses. As a result, the images analyzed were generally image pairs that were acquired under close-to-optimal conditions. Other processing techniques or approaches might enable analysis of both more challenging images (i.e., with greater differences in illumination or with less optimal stereo convergence angles), or provide more accurate results (i.e., using multiview stereo or more rigorous bundle adjustment). Nonetheless, the DTMs described are clearly useful for understanding 3D geological relationships, as illustrated here, and will be a useful basis for future analysis of craters and tectonic features common on the surface of Mercury.

\section{Acknowledgments}

This work would not have been possible without the effort of the development and public release of the Ames Stereo Pipeline. I would like to acknowledge the effort of all Ames Stereo Pipeline 
developers, past and present, especially Oleg Alexandrov, Ross Beyer, Scott McMichael, and Zachary Moratto. This work made extensive use of the USGS Integrated Software for Imagers and Spectrometers (ISIS) as well as the Geospatial Data Abstraction Library (GDAL), and the numerous developers of those packages are gratefully acknowledged. The MESSENGER science and engineering teams are thanked for obtaining the data that made this study possible. I also acknowledge Jay Dickson, Tim Goudge, Laura Kerber, and David Mayer for helpful discussions about Mercury and stereo image processing, and Claire Schwartz for assistance in the initial stages of this project. Three anonymous reviewers provided comments that have improved this manuscript. This work was supported by NASA grant NNX14AR88G.

\section{References}

Ames Stereo Pipeline Manual, 2015. The Ames Stereo Pipeline: NASA's Open Source Automated Stereogrammetry Software (user manual). http://ti.arc.nasa.gov/tech/asr/intelligent-robotics/ngt/stereo/\#Documentation

Anderson, J.A., Sides, S.C., Soltesz, D.L., Sucharski, T.L., Becker, K.J., 2004. Modernization of the integrated software for imagers and spectrometers, Lunar Planet. Sci. Conf, 35, abstract 2039.

Becker, K.J., B.A. Archinal, T. M. Hare, R.L. Kirk, E. Howington-Kraus, M.S. Robinson, M.R. Rosiek, 2015. Criteria for automated identification of stereo image pairs, Lunar Planet. Sci. Conf., 46, abstract 2703.

Beyer, R.A., 2015. An introduction to the data and tools of planetary geomorphology, Geomorphology, 240, 137-145, 10.1016/j.geomorph.2014.11.022.

Beyer, R.A., Alexandrov, O., Moratto, Z., 2014. Aligning terrain model and laser altimeter point clouds with the Ames Stereo Pipeline, Lunar Planet. Sci. Conf., 45, abstract 2902.

Blewett, D.T., Robinson, M.S., Denevi, B.W., Gillis-Davis, J.J., Head, J.W., Solomon, S.C., Holsclaw, G.M., McClintock, W.E., 2009. Multispectral imaging of Mercury from the first MESSENGER flyby: analysis of global and regional color trends. Earth Planet. Sci. Lett. 285, 272-282. 
Blewett, D.T., Chabot, N.L., Denevi, B.W., Ernst, C.M., Head, J.W., Izenberg, N.R., Murchie, S.L., Solomon, S.C., Nittler, L.R., McCoy, T.J., Xiao, Z., Baker, D.M.H., Fassett, C.I., Braden, S.E., Oberst, J., Scholten, F., Preusker, F., Hurwitz, D.M., 2011. Hollows on mercury: MESSENGER evidence for geologically recent volatile-related activity, Science, 333, 1856-1859, doi: 10.1126/science.1211681

Broxton, M. J. and L. J. Edwards. 2008. The Ames Stereo Pipeline: Automated 3D Surface Reconstruction from Orbital Imagery, Lunar Planet. Sci. Conf., 39, abstract 2419.

Cavanaugh, J.F., Smith, J.C., Sun, X., Bartels, A.E., Ramos-Izquierdo, L., Krebs, D.J., McGarry, J.F., Trunzo, R., Novo-Grandac, A. M., Britt, J.L., Karsh, J., Katz, R.B., Lukemire, A.T., Szymkiewicz, R., Berry, D.L., Swinski, J.P., Neumann, G.A., Zuber, M.T., Smith, D.E., The Mercury Laser Altimeter Instrument for the MESSENGER Mission, Space Sci. Rev., 131, 451-479, 10.1007/s11214-007-9273-4.

Cook, A.C., Robinson, M.S., 2000. Mariner 10 stereo image coverage of Mercury, J. Geophys. Res., 105, 9429-9443.

Di Achille, G., Zusi, M., Epifani, E.M., Popa, C., Galluzzi, V., Palumbo, P., 2014. High resolution morphometry of Mercury's candidate volcanic vents using Mercury Dual Imaging System (MDIS)-Derived Stereo Topography, Lunar Planet. Sci. Conf., 45, abstract 2035.

Fassett, C.I., Head, J.W., Blewett, D.T., Chapman, C.R., Dickson, J.L., Murchie, S.L., Solomon, S.C., Watters, T.R., 2009. Caloris impact basin: Exterior geomorphology, stratigraphy, morphometry, radial sculpture, and smooth plains deposits, Earth Planet. Sci. Lett., 285, 297308, 10.1016/j.epsl.2009.05.022.

Gaskell, R.W., Barnouin-Jha, O.S., Scheeres, D.J., Konopliv, A.S., Mukai, T., Abe, S., Saito, J., Ishiguro, M., Kubota, T., Hashimoto, T., Kawaguchi, J., Yoshikawa, M., Shirakawa, K., Kominato, T., Hirata, N., Demura, H., 2008. Characterizing and navigating small bodies with imaging data. Meteorit. Planet. Sci. 43, 1049-1061.

Gillis-Davis, J.J., Blewett, D.T., Gaskell, R.W., Denevi, B.W., Robinson, M.S., Strom, R.G., Solomon, S.C., Sprague, A.L., 2009. Pit-floor craters on Mercury: Evidence of near-surface igneous activity. Earth Planet. Sci. Lett. 285 (3-4), 243-250, 10.1016/j.eps1.2009.05.023.

Goudge, T.A., Head, J.W., Kerber, L., Blewett, D.T., Denevi, B.W., Domingue, D.L., GillisDavis, J.J., Gwinner, K., Helbert, J., Holsclaw, G.M., Izenburg, N.R., Klima, R.L., McClintock, W.E., Murchie, S.L., Neumann, G.A., Smith, D.E., Strom, R.G., Xiao, Z., Zuber, M.T., Solomon, S.C., 2014. Global inventory and characterization of pyroclastic deposits on Mercury: New insights into pyroclastic activity from MESSENGER orbital data, J. Geophys. Res.-Planets, 119, 635-658, 10.1002/2013JE004480.

Gwinner, K., Head, J.W., Oberst, J., Gillis-Davis, J.J., Xiao, Z., Strom, R.G., Preusker, F., Solomon, S.C., 2012. Morphology of Pit Craters on Mercury from Stereo-Derived 
Topography and Implications for Pit Crater Formation, Lunar Planet. Sci. Conf., 43, abstract 1991.

Hawke, B.R., Head, J.W., 1977. Impact melt on lunar crater rims. In: D.J. Roddy, R.O. Pepin, R.B. Merrill (Eds.), Impact and Explosion Cratering: Planetary and Terrestrial Implications, Pergamon Press, New York, pp. 815-841.

Hawkins III, S.E., Boldt, J.D., Darlington, E.H., Espiritu, R., Gold, R., Gotwols, B., Grey, M.P., Hash, C.D., Hayes, J.R., Jaskulek, S.E., Kardian Jr., C.J., Keller, M.R., Malaret, E.R., Murchie, S.L., Murphy, P.K., Peacock, K., Prockter, L.M., Reiter, A.R., Robinson, M.S., Schaefer, E.D., Shelton, R.G., Sterner II, R.E.. Taylor, H.W., Watters, T.R., Williams, B.D., 2007. The Mercury Dual Imaging System on the MESSENGER Spacecraft, Space Sci. Rev., 131, 247-338, 10.1007/s11214-007-9266-3.

Head, J.W., Murchie, S.L., Prockter, L.M., Robinson, M.S., Solomon, S.C., Strom, R.G., Chapman, C.R., Watters, T.R., McClintock, W.E., Blewett, D.T., Gillis-Davis, J.J., 2008. Volcanism on Mercury: evidence from the first MESSENGER flyby. Science 321, 69-72.

Head, J.W., Murchie, S.L., Prockter, L.M., Solomon, S.C., Chapman, C.R., Strom, R.G., Watters, T.R., Blewett, D.T., Gillis-Davis, J.J., Fassett, C.I., Dickson, J.L., Morgan, G.A., Kerber, L., 2009. Volcanism on Mercury: Evidence from the first MESSENGER flyby for extrusive and explosive activity and the volcanic origin of plains, Earth Planet. Sci. Lett., $285,227-242$.

Henriksen, M.R., Manheim, M.R., Becker, K.J., Howington-Kraus, E., and M.S. Robinson, 2015. High Resolution Regional Digital Terrain Models and Derived Products from MESSENGER MDIS NAC Images, Second Planetary Data Workshop, abstract 7009.

Kerber, L., Head, J.W., Solomon, S.C., Murchie, S.L., Blewett, D.T., Wilson, L., 2009. Explosive volcanic eruptions on Mercury: eruption conditions, magma volatile content, and implications for mantle volatile abundances. Earth Planet. Sci. Lett. 285, 263-271

Kerber, L., Head, J.W., Blewett, D.T., Solomon, S.C., Wilson, L., Murchie, S.L., Robinson, M.S., Denevi, B.W., Domingue, D.L., 2011. The global distribution of pyroclastic deposits on Mercury: The view from MESSENGER flybys 1-3, Planet. Space Sci., 59, 1895-1909, 10.1016/j.pss.2011.03.020.

Moratto, Z. M., M. J. Broxton, R. A. Beyer, M. Lundy, and K. Husmann. 2010. Ames Stereo Pipeline, NASA's Open Source Automated Stereogrammetry Software, Lunar Planet. Sci. Conf., 41, abstract 2364.

Murchie, S.L., Watters, T.R., Robinson, M.S., Head, J.W., Strom, R.G., Chapman, C.R., Solomon, S.C., McClintock, W.E., Prockter, L.M., Domingue, D.L., Blewett, D.T., 2008. Geology of the Caloris basin, Mercury: a view from MESSENGER. Science, 321, 73-76. 
Oberst, J., Preusker, F., Phillips, R., Watters, T.R., Head, J.W., Zuber, M.T., Solomon, S.C., 2010. The morphology of Mercury's Caloris basin as seen in MESSENGER stereo topographic models, Icarus, 209, 230-238, 10.1016/j.icarus.2010.03.009.

Preusker, F, Oberst, J., Head, J.W., Watters, T.R., Robinson, M.S., Zuber, M.T., Solomon, S.C., 2011. Stereo topographic models of Mercury after three MESSENGER flybys, Planetary Space Sci., 59, 1910-1917.

Preusker, F, Oberst, J. Blewett, D.T., Gwinner, K., Head, J.W., Murchie, S.L., Robinson, M.S., Watters, T.R., Zuber, M.T., Solomon, S.C., 2012. Topography of Mercury from Stereo Images: First Samples from MESSENGER Orbital Mapping, Lunar Planet. Sci. Conf., 43, 1913.

Prockter, L.M. and 13 co-authors, 2016. The first global geological map of Mercury, Lunar Planet. Sci. Conf., 37, 1245.

Robinson, M.S., Murchie, S.L., Blewett, D.T., Domingue, D.L., Hawkins, S.E., Head, J.W., Holsclaw, G.M., McClintock, W.E., McCoy, T.J., McNutt, R.L., Prockter, L.M., Solomon, S.C., Watters, T.R., 2008. Reflectance and color variations on Mercury: indicators of regolith processes and compositional heterogeneity. Science, 321, 66-69.

Rothery, D.A., Thomas, R.J., Kerber, L., 2014. Prolonged eruptive history of a compound volcano on Mercury: Volcanic and tectonic implications, Earth Planet. Sci. Lett., 385, 59-67.

Schon, S.C., Head, J.W., Baker, D.M.H., Ernst, C.M., Prockter, L.M., Murchie, S.L., Solomon, S.C., 2011. Eminescu impact structure: Insight into the transition from complex crater to peak-ring basin on Mercury, Planet. Space Sci., 59, 1949-1959, 10.1016/j.pss.2011.02.003.

Schultz, P.H., 1977. Endogenic modification of impact craters on Mercury. Phys. Earth Planet. Inter. 15, 202-219.

Shean, D.E., Alexandrov, O., Moratto, Z.M., Smith, B.E., Joughin, I.R., Porter, C., Morin, P., 2016. An automated, open-source pipeline for mass production of digital elevation models (DEMs) from very-high-resolution commercial stereo satellite imagery, ISPRS Journal of Photogrammetry and Remote Sensing, 116, 101-117, 10.1016/j.isprsjprs.2016.03.012.

Solomon, S.C., McNutt, R.L., Gold, R.E., Domingue, D.L. (2007), MESSENGER Mission Overview, Space Sci. Rev., 131, 3-39, doi:10.1007/s11214-007-9247-6.

Thomas, R.J., Rothery, D.A., Conway, S.J., Anand, M., 2014a. Long-lived explosive volcanism on Mercury, Geophys. Res. Lett., 41, 6084-6092, 10.1002/2014GL061224.

Thomas, R.J., Rothery, D.A., Conway, S.J., Anand, M., 2014b. Mechanisms of explosive volcanism on Mercury: Implications from its global distribution and morphology, $\mathrm{K}$. Geophys. Res.-Planets, 119, 2239-2254, 10.1002/2014JE004692. 
Thomas, R.J., Rothery, D.A., Conway, S.J., Anand, M., 2014c. Hollows on Mercury: Materials and mechanisms involved in their formation, Icarus, 229, 221-235, 10.1016/j.icarus.2013.11.018.

Thomas, R.J., Lucchetti, A., Cremonese, G., Rothery, D.A., Massironi, M., Re, Christina, Conway, S.J., Anand, M., 2015. A cone on Mercury: Analysis of a residual central peak encircled by an explosive volcanic vent, Planet. Space Sci, 108, 108-116, 10.1016/j.pss.2015.01.005.

Vaughan, W.M., Helbert, J., Blewett, D.T., Head, J.W., Murchie, S.L., Gwinner, K., McCoy, T.J., Solomon, S.C., 2012. Hollow-forming layers in impact craters on Mercury: Massive sulfide or chloride deposits formed by impact melt differentiation? Lunar Planet. Sci. Conf., 43, abstract 1187.

Watters, W.A., Geiger, L.M., Fendrock, M.A., Gibson, R., 2015. Morphometry of small recent impact craters on Mars: Size and terrain dependence, short-term modification, J. Geophys. Res.-Planets, 120, 226-254, 10.1002/2014JE004630.

Zuber, M.T. and 23 co-authors, 2012. Topography of the Northern Hemisphere of Mercury from MESSENGER Laser Altimetry, Science, 336, 217-220, 10.1126/science.1218805. 


\begin{tabular}{|l|l|}
\hline Emission angle of images & $e<60^{\circ}$ \\
\hline Incidence angle of images & $40^{\circ}<i<72^{\circ}$ \\
\hline Ratio of image resolutions & $r_{1} / r_{2}<2.5 \times, r_{2} / r_{1}<2.5 \times$ \\
\hline Parallax/height ratio (see Becker et al., 2015) & $0.1 \leq d p \leq 1$ \\
\hline Shadow-tip Distance (see Becker et al., 2015) & $0 \leq d s h \leq 2.58$ \\
\hline Overlapping Pixels (exclude small matching areas) & \# overlapping pixels $\geq 90000$ \\
\hline
\end{tabular}

Table 1. Criteria used for selecting stereo pairs (after Becker et al., 2015). Note that some of the thresholds set here are optimistic, at least with MESSENGER data: stereo pairs with high $d s h$ and/or $d p$ far from optimal values of $~ 0.4-0.6$ did not always prove to be amenable to producing useful results. In particular, the best DTMs produced in this study tended to have very little change in illumination and shadowing between images (i.e., $d s h \leq 0.02$ ). 


\begin{tabular}{|l|l|}
\hline Alignment-method & Homography \\
\hline Force-use-entire-range & True \\
\hline Correlation Kernel Size & $31 \times 31$ pixels \\
\hline Subpixel Mode & 2 (affine adaptive window) \\
\hline Subpixel-Kernel & $21 \times 21$ pixels \\
\hline Filter-mode, rm-min-matches & $2,80 \%$ \\
\hline
\end{tabular}

Table 2. Parameters in stereo.default. Parameters not listed were set to the default. Unprojected images were passed to stereo for processing. Filtering was also used when converting the point clouds to DTMs to exclude points with the high triangulation errors $(>3 \sigma$ of the median triangulation error). 


\begin{tabular}{|c|c|c|c|c|c|}
\hline Name & $\begin{array}{c}\text { \# of } \\
\text { source } \\
\text { image } \\
\text { pairs }\end{array}$ & $\begin{array}{c}\text { DTM } \\
\text { Post Res. } \\
\text { (m) }\end{array}$ & $\begin{array}{l}\text { MAD from } \\
\text { MLA, pre- } \\
\text { alignment } \\
\text { (m) }\end{array}$ & $\begin{array}{l}\text { MAD from } \\
\text { MLA, post- } \\
\text { alignment (m) }\end{array}$ & Features of interest \\
\hline 16E57N_0 & 67 & 65 & 396.6 & 39.1 & Hokusai Crater; Secondaries. \\
\hline 17E67N_0 & 18 & 70 & 187.9 & 20.2 & Craters; Plains; Secondaries \\
\hline 18E57N_0 & 11 & 65 & 292.8 & 14.5 & Hokusai Crater; Impact Melt \\
\hline 21E55N_0 & 13 & 55 & 69.7 & 24.7 & Craters; Plains; Secondaries \\
\hline 23E33N_0 & 28 & 95 & 344.0 & 52.9 & Craters; Pit \\
\hline 25E65N_0 & 14 & 50 & 360.3 & 44.5 & Craters; Graben; Plains \\
\hline 36E60N_0 & 12 & 55 & 151.7 & 20.2 & Craters; Plains; Graben; Ghost Crater \\
\hline 41E20N_0 & 27 & 110 & 225.8 & 83.6 & Calypso Rupes; Craters; Scarp(s) \\
\hline 43E19N_0 & 15 & 125 & 334.2 & 146.2 & Calypso Rupes; Craters; Plains; Scarp(s) \\
\hline 44E59N_0 & 42 & 115 & 174.3 & 13.5 & Craters; Plains; Wrinkle Ridges \\
\hline 45E20N_0 & 9 & 170 & 354.6 & 68.9 & Calypso Rupes; Craters; Plains; Scarp(s) \\
\hline 47E21N_0 & 10 & 155 & 148.6 & 139.1 & Calypso Rupes; Craters; Plains; Scarp(s) \\
\hline 55E13N_0 & 6 & 175 & 184.8 & 72.8 & Craters; Plains; Scarp(s) \\
\hline 64E36N_0 & 44 & 110 & 283.0 & 30.3 & Craters; NE Rachmaninoff Pit \\
\hline 66E14S_0 & 7 & 225 & $\mathrm{n} / \mathrm{a}$ & $\mathrm{n} / \mathrm{a}$ & Craters; Plains; Secondaries \\
\hline 67E13N_0 & 5 & 170 & 1000.8 & 47.7 & Craters; Plains; Ghost Craters; Secondaries \\
\hline 72E20S_0 & 12 & 200 & $\mathrm{n} / \mathrm{a}$ & $\mathrm{n} / \mathrm{a}$ & Kipling Crater; Capote Crater; Pits; Plains \\
\hline 77E18N_0 & 12 & 115 & 422.7 & 148.4 & Craters; Plains; Scarp(s) \\
\hline 77E8N_0 & 10 & 150 & 244.6 & 57.8 & Craters; Plains; Scarp(s) \\
\hline 84E15N_0 & 11 & 130 & 165.4 & 116.0 & Craters; Scarp(s); Secondaries \\
\hline 84E26N_0 & 7 & 125 & 87.0 & 58.2 & Craters; Plains; Scarp(s) \\
\hline 85E28N_0 & 7 & 165 & 85.7 & 74.9 & Craters; Plains; Scarp(s) \\
\hline 88E30N_0 & 8 & 150 & 129.0 & 68.1 & Craters; Plains; Scarp(s); Wrinkle Ridge \\
\hline 89E32N_0 & 9 & 140 & 152.0 & 60.9 & Craters; Plains; Scarp(s); Secondaries \\
\hline 90E29N_0 & 10 & 120 & 76.5 & 65.0 & Craters; Plains; Scarp(s); Secondaries \\
\hline 92E39N_0 & 12 & 45 & 424.5 & 24.4 & Craters; Plains; Scarp(s); Secondaries \\
\hline 93E29N_0 & 8 & 125 & 243.9 & 63.4 & Craters; Plains; Scarp(s); Secondaries \\
\hline 93E30N_0 & 9 & 150 & 185.4 & 79.7 & Craters; Plains; Scarp(s); Secondaries \\
\hline 94E16N_0 & 11 & 160 & 155.8 & 93.6 & Craters; Ejecta \\
\hline 94E32N_0 & 7 & 140 & 290.3 & 62.6 & Fonteyn Crater; Craters; Plains \\
\hline 102E30N_0 & 9 & 135 & 94.4 & 50.2 & Craters \\
\hline 103E40N_0 & 14 & 115 & 96.9 & 66.5 & Craters; Plains; Scarp(s) \\
\hline 106E52N_0 & 20 & 190 & 344.5 & 271.4 & Craters; Plains; WAC \\
\hline 107E29N_0 & 9 & 135 & 211.2 & 31.8 & Craters; Scarp(s) \\
\hline 109E19N_0 & 7 & 175 & 181.5 & 78.4 & Craters; Plains; Secondaries \\
\hline 111E32N_0 & 10 & 130 & 253.7 & 78.8 & Craters \\
\hline 113E0N_0 & 9 & 220 & $\mathrm{n} / \mathrm{a}$ & $\mathrm{n} / \mathrm{a}$ & Craters; Plains; Scarp(s) \\
\hline 114E11N_0 & 69 & 170 & 1228.0 & 80.3 & Eminescu Crater; Plains; Ejecta; Central Peaks \\
\hline 114E11N_1 & 45 & 170 & 573.9 & 77.9 & Eminescu Crater; Plains; Ejecta; Central Peaks \\
\hline 117E28N_0 & 40 & 105 & 70.9 & 28.5 & Raditladi Crater; Crater; Peak Ring; Plains; \\
\hline
\end{tabular}




\begin{tabular}{|c|c|c|c|c|c|}
\hline Name & $\begin{array}{c}\text { \# of } \\
\text { source } \\
\text { image } \\
\text { pairs }\end{array}$ & $\begin{array}{c}\text { DTM } \\
\text { Post Res. } \\
\text { (m) }\end{array}$ & $\begin{array}{l}\text { MAD from } \\
\text { MLA, pre- } \\
\text { alignment } \\
\text { (m) }\end{array}$ & $\begin{array}{l}\text { MAD from } \\
\text { MLA, post- } \\
\text { alignment (m) }\end{array}$ & Features of interest \\
\hline & & & & & Pits \\
\hline 118E26N_0 & 62 & 160 & 380.5 & 143.2 & $\begin{array}{l}\text { Raditladi Crater; Craters; Peak Ring; Plains; } \\
\text { Ejecta; Graben }\end{array}$ \\
\hline 119E28N_0 & 11 & 145 & 98.1 & 80.9 & $\begin{array}{l}\text { Raditladi Crater; Craters; Peak Ring; Plains; } \\
\text { Pits }\end{array}$ \\
\hline 121E27N_0 & 18 & 115 & 281.2 & 52.6 & $\begin{array}{l}\text { Raditladi Crater; Craters; Peak Ring; Plains; } \\
\text { Hollows }\end{array}$ \\
\hline 121E27N_1 & 9 & 60 & 108.2 & 57.3 & Raditladi Crater; Craters; Peak Ring; Hollows \\
\hline 124E35N_0 & 10 & 125 & 477.2 & 43.7 & Craters; Scarp(s); Secondaries \\
\hline 130E18N_0 & 9 & 205 & 150.5 & 58.1 & Craters; Plains; Scarp(s); Knobs \\
\hline 131E5N_0 & 4 & 110 & $\mathrm{n} / \mathrm{a}$ & $\mathrm{n} / \mathrm{a}$ & Caloris Sculpture; Knobs \\
\hline 135E23N_0 & 9 & 180 & 116.9 & 82.6 & Craters; Knobs; Secondaries; Scarp(s) \\
\hline 145E22N_0 & 20 & 180 & 1808.5 & 45.9 & Caloris Pits; Knobs; Wrinkle Ridges \\
\hline 154E43N_0 & 5 & 90 & $\mathrm{n} / \mathrm{a}$ & $\mathrm{n} / \mathrm{a}$ & Sander Crater; Secondaries \\
\hline 204E17N_0 & 7 & 140 & 172.0 & 35.7 & Craters; Plains; Scarp(s) \\
\hline 212E3S_0 & 6 & 130 & 1617.5 & 34.5 & Zeami Crater; Hollows (noisy) \\
\hline 212E3S_1 & 3 & 150 & 242.6 & 51.7 & Zeami Crater; Hollows (noisy) \\
\hline 214E70N_0 & 9 & 245 & 51.7 & 26.4 & Craters; WAC \\
\hline 233E37N_0 & 10 & 95 & 385.3 & 71.7 & Degas Crater \\
\hline 234E0N_0 & 6 & 140 & $\mathrm{n} / \mathrm{a}$ & $\mathrm{n} / \mathrm{a}$ & Mena Crater; Craters; Plains; Wrinkle Ridge \\
\hline 234E32N_0 & 11 & 80 & 349.4 & 41.9 & Crater Rim; Plains \\
\hline 241E22N_0 & 13 & 165 & 113.6 & 20.8 & Durer Crater; Craters; Plains; Peak Ring \\
\hline 242E22N_0 & 11 & 110 & 135.0 & 48.1 & Durer Crater; Craters; Plains; Peak Ring \\
\hline 248E8N_0 & 28 & 170 & 141.4 & 68.3 & Craters; Plains; Wrinkle Ridges; Scarp(s) \\
\hline 251E23N_0 & 10 & 120 & 293.5 & 82.8 & Craters; Secondaries \\
\hline 255E7S_0 & 6 & 200 & $\mathrm{n} / \mathrm{a}$ & $\mathrm{n} / \mathrm{a}$ & Craters; Plains \\
\hline 255E9S_0 & 5 & 210 & $\mathrm{n} / \mathrm{a}$ & $\mathrm{n} / \mathrm{a}$ & Waters Crater; Craters; Impact Melt Tongue \\
\hline 256E9N_0 & 11 & 135 & 496.3 & 345.8 & Wang Meng Crater \\
\hline 260E17N_0 & 11 & 105 & 152.7 & 89.1 & $\begin{array}{l}\text { Craters; Plains; Wrinkle Ridge. Note: fairly } \\
\text { noisy }\end{array}$ \\
\hline 267E25N_0 & 11 & 135 & 222.3 & 67.0 & Craters; Scarp(s) \\
\hline 273E14N_0 & 8 & 175 & 595.2 & 115.8 & Vivaldi Crater \\
\hline 275E15N_0 & 12 & 70 & $\mathrm{n} / \mathrm{a}$ & $\mathrm{n} / \mathrm{a}$ & Vivaldi Crater \\
\hline 277E38N_0 & 11 & 115 & 173.1 & 59.7 & Craters \\
\hline 281E52N_0 & 9 & 45 & $\mathrm{n} / \mathrm{a}$ & $\mathrm{n} / \mathrm{a}$ & Stravinsky Crater \\
\hline 292E0N_0 & 10 & 125 & $\mathrm{n} / \mathrm{a}$ & $\mathrm{n} / \mathrm{a}$ & Polygnotus Crater; Plains \\
\hline 293E22N_0 & 10 & 70 & 278.6 & 90.8 & Catullus Crater; Pit; Scarp(s) (Fig. 3) \\
\hline 293E22N_1 & 8 & 160 & 91.5 & 82.9 & Catullus Crater; Pit; Scarp(s) (Fig. 3) \\
\hline 296E2N_0 & 31 & 225 & $\mathrm{n} / \mathrm{a}$ & $\mathrm{n} / \mathrm{a}$ & Craters; Plains \\
\hline 296E34N_0 & 11 & 130 & 458.1 & 70.5 & Craters \\
\hline 296E3S_0 & 9 & 230 & $\mathrm{n} / \mathrm{a}$ & $\mathrm{n} / \mathrm{a}$ & Thakur Crater; Craters; Plains; Scarp(s) \\
\hline
\end{tabular}




\begin{tabular}{|c|c|c|c|c|c|}
\hline Name & $\begin{array}{l}\text { \# of } \\
\text { source } \\
\text { image } \\
\text { pairs }\end{array}$ & $\begin{array}{c}\text { DTM } \\
\text { Post Res. } \\
(\mathrm{m})\end{array}$ & $\begin{array}{l}\text { MAD from } \\
\text { MLA, pre- } \\
\text { alignment } \\
(\mathrm{m})\end{array}$ & $\begin{array}{c}\text { MAD from } \\
\text { MLA, post- } \\
\text { alignment (m) }\end{array}$ & Features of interest \\
\hline 297E13N_0 & 7 & 95 & $\mathrm{n} / \mathrm{a}$ & $\mathrm{n} / \mathrm{a}$ & Crater; Hollows \\
\hline 297E13N_1 & 5 & 100 & $\mathrm{n} / \mathrm{a}$ & $\mathrm{n} / \mathrm{a}$ & Crater; Hollows \\
\hline 299E27N_0 & 24 & 125 & 249.4 & 81.7 & Praxiteles Crater; Craters; Plains; Pits (Fig. 4) \\
\hline 300E26N_0 & 15 & 60 & 502.2 & 20.3 & Praxiteles Crater; Craters; Plains; Pits (Fig. 4) \\
\hline 301E27N_0 & 106 & 55 & 412.9 & 74.1 & $\begin{array}{l}\text { Praxiteles Crater; Craters; Plains; Hollows; } \\
\text { Pits (Fig. 4) }\end{array}$ \\
\hline 303E33N_0 & 33 & 135 & 346.9 & 71.5 & Craters; Secondaries \\
\hline 304E6N_0 & 8 & 190 & $\mathrm{n} / \mathrm{a}$ & $\mathrm{n} / \mathrm{a}$ & Craters; Pit; Scarp(s) \\
\hline 307E37N_0 & 11 & 125 & 331.6 & 62.6 & Velazquez Crater; Craters; Peak Ring \\
\hline 307E58N_0 & 13 & 60 & 124.8 & 22.0 & $\begin{array}{l}\text { Carnegie Rupes; Duccio Crater; Craters; } \\
\text { Scarp(s) }\end{array}$ \\
\hline 311E16N_0 & 10 & 155 & 639.1 & 57.9 & Lermontov Crater; Pit \\
\hline 314E29N_0 & 8 & 175 & 252.9 & 84.5 & Craters; Secondaries; Scarp(s) \\
\hline 317E37N_0 & 6 & 145 & 304.4 & 30.2 & Craters \\
\hline 319E30N_0 & 9 & 140 & 581.4 & 57.8 & Craters; Secondaries; Scarp(s) \\
\hline 320E29N_0 & 9 & 145 & 527.7 & 83.9 & Craters; Secondaries; Scarp(s) \\
\hline 322E23N_0 & 11 & 150 & 3117.0 & 640.5 & Craters \\
\hline 327E47N_0 & 5 & 65 & 1402.5 & 16.9 & Craters \\
\hline 328E28N_0 & 6 & 165 & 382.5 & 100.3 & Craters; Wrinkle Ridge \\
\hline 328E32N_0 & 9 & 135 & 199.3 & 87.8 & Craters; Plains; Scarp(s); Secondaries \\
\hline 329E30N_0 & 6 & 150 & 375.0 & 78.1 & Craters; Wrinkle Ridge \\
\hline 359E56N_0 & 28 & 50 & 146.9 & 27.4 & Craters; Plains; Wrinkle Ridge; Secondaries \\
\hline
\end{tabular}

Table 3. The list of DTMs created as part of this project. Column one is the DTM name, defined using the nearest whole longitude and latitude to its center; where two DTMs share the same center, the first is " 0 ", the second is " 1 ", etc). Column two is the number of source image pairs that contributed to the mosaic. Column three is the post resolution in meters, chosen to be a factor of $3 \times$ the source image resolution at that location. Columns four and five are comparisons of the DTMs with MLA, using the median absolute deviation (MAD), before and after coalignment with MLA. Where this is given as "n/a" there was no MLA data to co-align the DTM to and to compare with. In those cases, the relative values in the DTMs are potentially useful but the absolute elevations are potentially offset by hundreds of meters. Column seven provides some description of the geologic features observed. Note that hollows are only occasionally resolved in the topography (the best examples are in DTMs with $\leq 100 \mathrm{~m} /$ pixel resolution, 121E27N_1, 297E13N_0 and 297E13N_1, and 300E26N_0 and 301E27N_0 (Fig. 4)). 


\begin{tabular}{|l|c|c|c|l|c|c|c|c|c|}
\hline Pit Name & $\begin{array}{l}\text { Lon. } \\
\left({ }^{\circ}\right)\end{array}$ & $\begin{array}{l}\text { Lat. } \\
\left({ }^{\circ}\right)\end{array}$ & DTM Name & $\begin{array}{l}\text { Depth } \\
(\mathrm{m})\end{array}$ & Area $\left(\mathrm{m}^{2}\right)$ & $\begin{array}{l}\text { Volume } \\
\left(\mathrm{m}^{3}\right)\end{array}$ & $\begin{array}{l}\text { Ext. Slope } \\
(\text { Degrees })\end{array}$ & $\begin{array}{l}\text { Int. Slope } \\
(\text { Degrees })\end{array}$ & Multiple? \\
\hline NE Rach. & 64.0 & 35.8 & 64E36N_0 & 3.99E+03 & $7.98 \mathrm{E}+08$ & $1.51 \mathrm{E}+12$ & -3.8 & -26.6 & Yes \\
\hline Kipling1 & 72.0 & -18.5 & 72E20S_0 & $1.93 \mathrm{E}+03$ & $1.29 \mathrm{E}+08$ & $1.09 \mathrm{E}+11$ & -1.5 & -23.0 & No \\
\hline NE Hodgkins & 22.8 & 32.0 & 23E33N_0 & $1.82 \mathrm{E}+03$ & $5.55 \mathrm{E}+08$ & $5.37 \mathrm{E}+11$ & -1.1 & -22.4 & Yes \\
\hline Catullus & -67.4 & 21.8 & 293E22N_1 & $1.76 \mathrm{E}+03$ & $1.68 \mathrm{E}+08$ & $1.16 \mathrm{E}+11$ & -0.3 & -21.7 & No (?) \\
\hline Caloris1 & 146.2 & 22.3 & $145 \mathrm{E} 22 \mathrm{~N} \_0$ & $1.75 \mathrm{E}+03$ & $2.96 \mathrm{E}+08$ & $2.26 \mathrm{E}+11$ & -0.9 & -17.4 & Yes \\
\hline Kipling2 & 72.6 & -21.0 & 72E20S_0 & $1.75 \mathrm{E}+03$ & $1.81 \mathrm{E}+08$ & $1.17 \mathrm{E}+11$ & -1.7 & -23.9 & No \\
\hline Kipling3 & 71.3 & -19.0 & 72E20S_0 & $1.69 \mathrm{E}+03$ & $3.88 \mathrm{E}+08$ & $2.76 \mathrm{E}+11$ & -2.2 & -15.9 & Yes \\
\hline Praxiteles & -59.0 & 26.8 & 301E27N_0 & $1.07 \mathrm{E}+03$ & $1.30 \mathrm{E}+08$ & $7.18 \mathrm{E}+10$ & -0.6 & -18.9 & No \\
\hline Caloris2 & 145.8 & 21.9 & 145E22N_0 & $9.17 \mathrm{E}+02$ & $1.21 \mathrm{E}+08$ & $4.46 \mathrm{E}+10$ & -0.2 & -14.8 & Yes \\
\hline Lermontov & -48.0 & 15.8 & 311E16N_0 & $8.98 \mathrm{E}+02$ & $7.24 \mathrm{E}+07$ & $3.07 \mathrm{E}+10$ & -1.0 & -19.4 & No (?) \\
\hline W Mistral & -55.8 & 5.4 & 304E6N_0 & $7.96 \mathrm{E}+02$ & $7.75 \mathrm{E}+07$ & $2.51 \mathrm{E}+10$ & 1.6 & -13.4 & No (?) \\
\hline Caloris3 & 145.3 & 21.8 & 145E22N_0 & $7.77 \mathrm{E}+02$ & $1.34 \mathrm{E}+08$ & $4.48 \mathrm{E}+10$ & -0.8 & -11.4 & Yes \\
\hline Caloris4 & 143.9 & 21.9 & 145E22N_0 & $7.26 \mathrm{E}+02$ & $3.23 \mathrm{E}+07$ & $8.79 \mathrm{E}+09$ & 0.9 & -14.0 & No \\
\hline Caloris5 & 144.0 & 21.8 & 145E22N_0 & $7.02 \mathrm{E}+02$ & $1.47 \mathrm{E}+07$ & $4.26 \mathrm{E}+09$ & -0.3 & -18.4 & No \\
\hline Caloris6 & 145.6 & 21.6 & 145E22N_0 & $4.55 \mathrm{E}+02$ & $4.60 \mathrm{E}+07$ & $1.04 \mathrm{E}+10$ & -1.0 & -10.1 & Yes (?) \\
\hline Zeami & -147.3 & -3.0 & 212E3S_0 & $4.02 \mathrm{E}+02$ & $2.77 \mathrm{E}+07$ & $5.14 \mathrm{E}+09$ & -0.3 & -8.8 & Yes (?) \\
\hline
\end{tabular}

Table 4. Observations of large pits in the stereo DTMs. Slopes are measured from the median profiles over a $2 \mathrm{~km}$ baseline away from the rim; negative angles are downsloping (away from the rim). Multiple vents are inferred for some of the pits on the basis of multiple minima in the topography of the pit interiors. 
Figure Captions

Figure 1. (a) All MDIS data meeting the thresholds defined in Table 1 (NAC data in red, WAC (G filter) in blue). The gaps at longitudes $\sim 0^{\circ}$ and $180^{\circ}$ are a result of MESSENGER's orbit; the exclusion of the poles is a result of the applied incidence angle threshold and Mercury's nearzero obliquity. (b) The subset of the data that meet the thresholds in Table 1 but adding the restriction that each image have resolution less than $100 \mathrm{~m} /$ pixel. The white dots show the location of the DTMs produced as part of this project (see Table 3).

Figure 2. (a) Two digital terrain models of Eminescu crater (Schon et al., 2011) and its immediate surroundings. 69 source image pairs went into creating the east-west DTM, 114E11N_0, and 45 source image pairs went into creating 114E11N_1; the median resolution of the source images for the two DTMs were 59 and $57 \mathrm{~m} /$ pixel, respectively. Hollows (Blewett et al., 2011) surrounding the central peak are below the resolution of these DTMs, but many other features of interest are well-resolved, especially the crater's rim, terraces, and small peak ring. Small, smooth ponds of impact melt are observed just outside the rim (especially to the west and south). The range of elevations for the color ramp is from $-2500 \mathrm{~m}$ (white) to $1500 \mathrm{~m}$ (red). (b) Comparison of topographic profiles from MLA shots (located by red point profile in (a)) and the two stereo DTMs at this location (note the offset for clarity). These three datasets agree well, with some local differences, for example, in the rough parts of the crater floor, where the stereo data appears to resolve real roughness missed by MLA; in addition, the central peaks were not captured in the filtered MLA data. 
Figure 3. (a) Two digital terrain models of Catullus crater and its central pit. The north-south DTM, 293E22N_0, was created using 10 source image pairs with median resolution 24 m/pixel; the east-west DTM, 293E22N_0, was created using 8 source image pairs with median resolution $62 \mathrm{~m} /$ pixel. The range of elevations for the color ramp is from $-2000 \mathrm{~m}$ (white) to $1500 \mathrm{~m}$ (red). (b) Comparison of topographic profiles from MLA shots (red point profile in (a)) and the two stereo DTMs at this location (note the offset for clarity).

Figure 4. Three digital terrain models of Praxiteles crater and its pits and hollows. The eastwest DTM, 299E27N_0, covering the broadest region, was created with 24 source image pairs with median resolution 43 m/pixel; the two other DTMs, 300E26_0 and 301E27N_0 had 15 and 106 source image pairs respectively, with median resolution of 22 and $24 \mathrm{~m} /$ pixel. As illustrated in the profiles, the high resolution afforded by these DTMs resolved some hollows, despite their small horizontal extent and limited topography. (Profiles here are measured on 301E27N_0; the hollows are located by the black arrow; the large pit is located by the white arrow). The range of elevations for the color ramp is from $-2500 \mathrm{~m}$ (white) to $1500 \mathrm{~m}$ (red).

Figure 5. Frequency histogram showing the number of mapped hollows of a given depth in meters.

Figure 6. Median profiles of (a) larger and (b) smaller pits, and (c) the relationship between exterior slope and pit volume (see also Table 4). There appears to be a correlation between size and the existence of an appreciable exterior slope: larger pits such as NE Rachmoninoff, NE 
Hodgkins, Caloris1, and all three Kipling pits have either a rim or a broader rise, while most of the smaller pits have exterior slopes that are close to zero. 


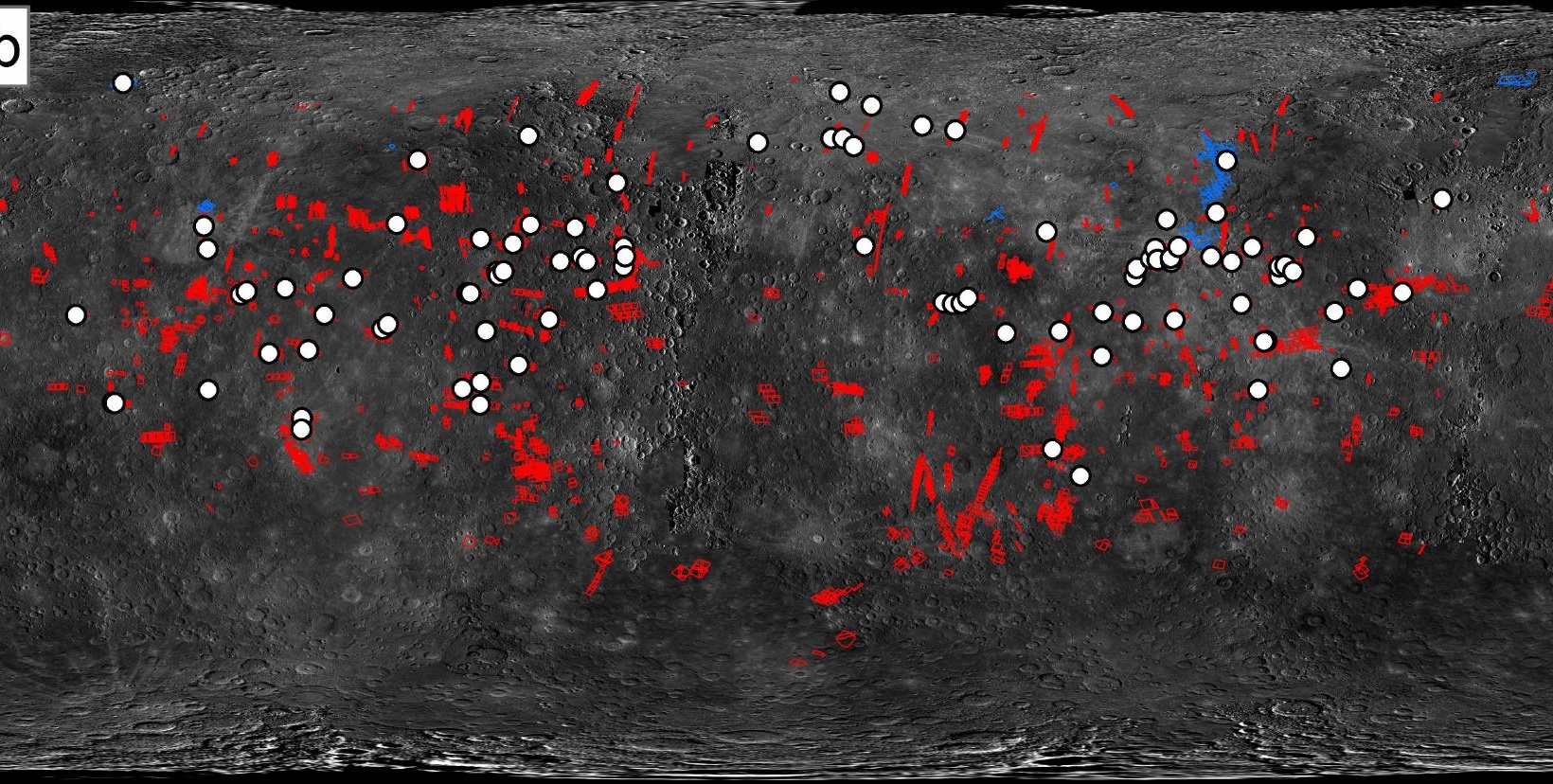




\section{a,${ }^{3}$}

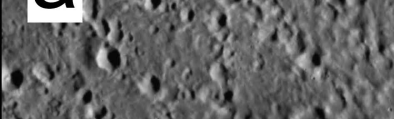
(4. (4) 4 ,

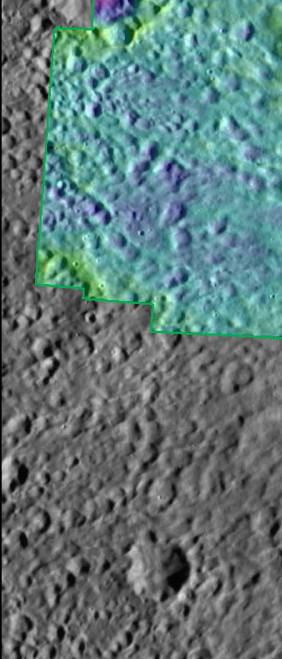

b

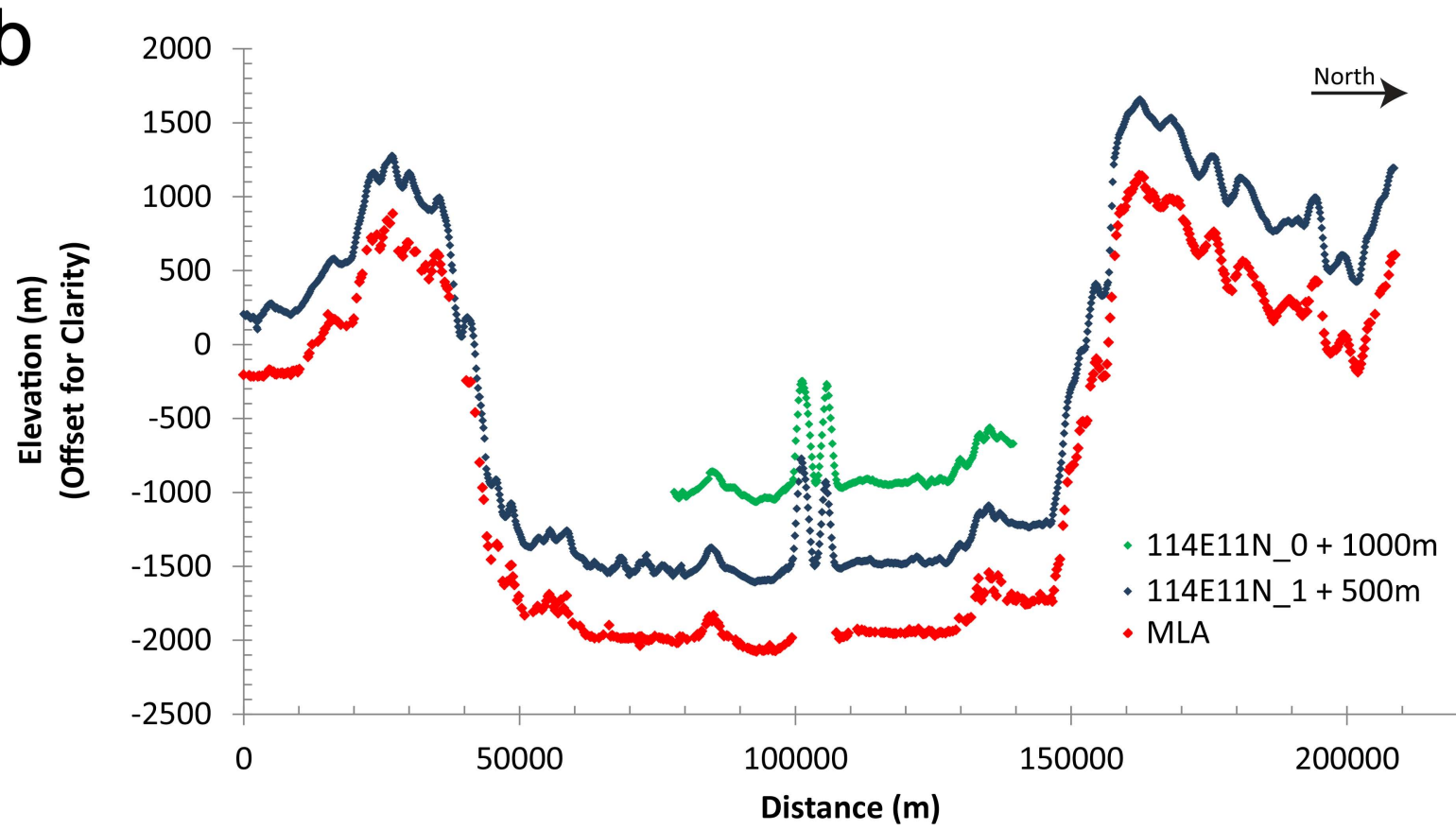

3.
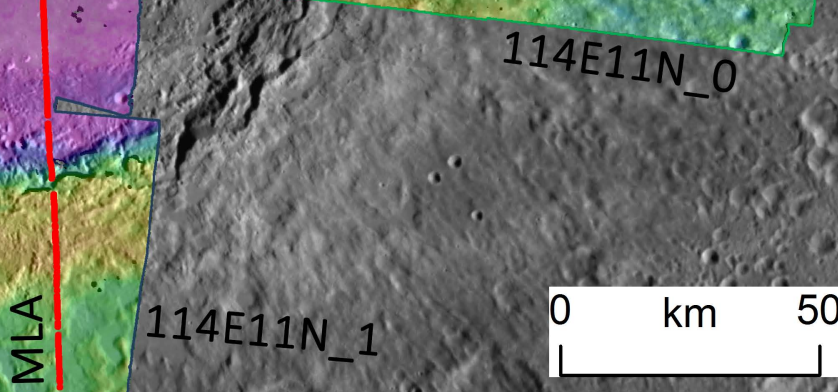

38

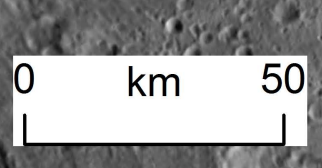




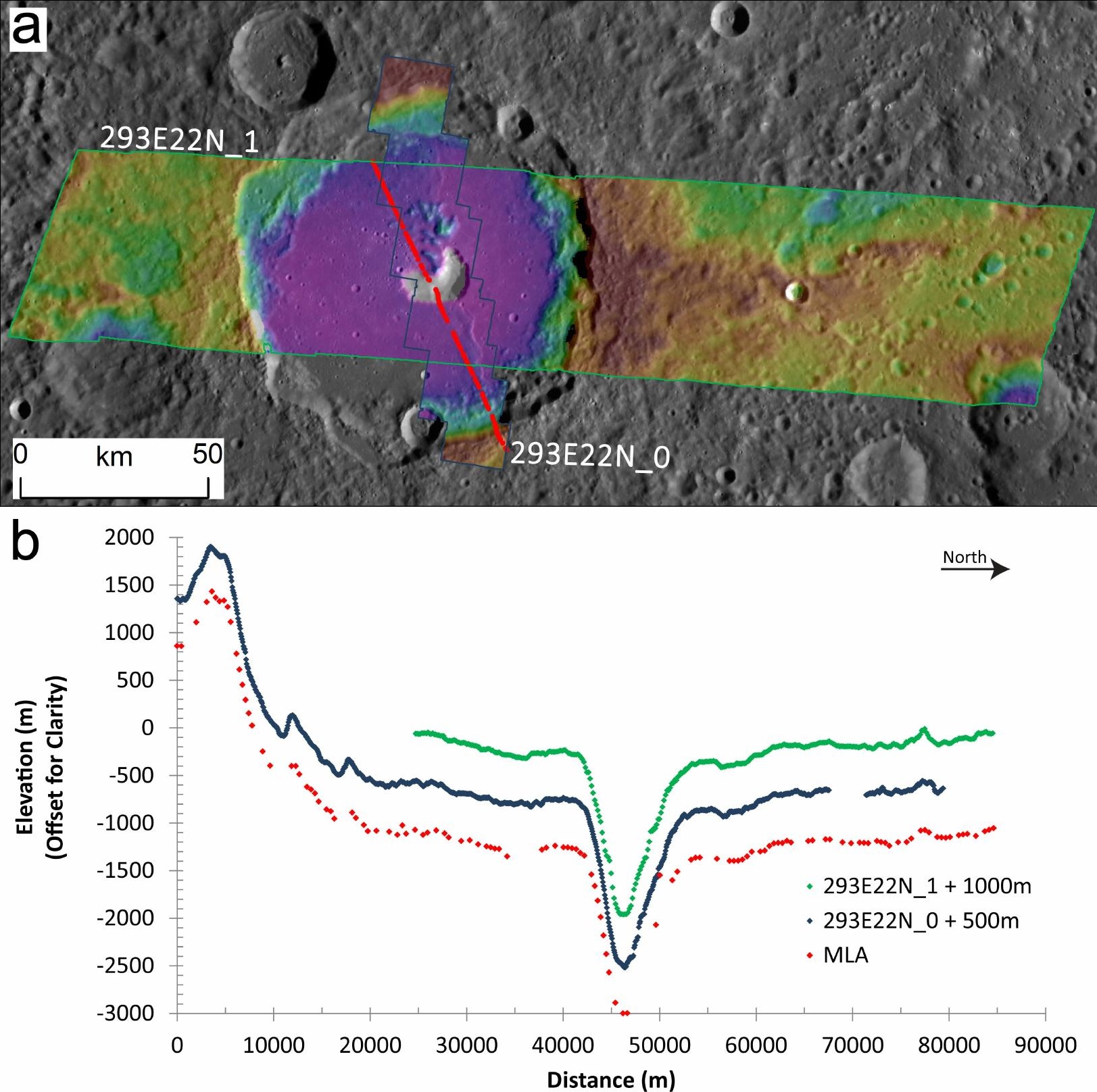

\section{à}

C6 293E22N_1

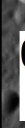

b Distance (m) 
